\title{
Glutamate-activated Currents in Outside-out Patches from Spiny versus Aspiny Hilar Neurons of Rat Hippocampal Slices
}

\author{
Charles T. Livsey, Erminio Costa, and Stefano Vicini \\ FIDIA-Georgetown Institule for the Neurosciences and Department of Pharmacology, Georgetown University School of \\ Medicine, Washington, D.C. 20007
}

\begin{abstract}
The desensitization rate of non-NMDA glutamate receptors was investigated in outside-out membrane patches obtained from morphologically identified spiny "'mossy cells"' (SMCs) and aspiny hilar interneurons (AHIs) in young rat hippocampal slices. The fast application of a $1 \mathrm{~mm}$ step of L-glutamate for 50-100 msec in the presence of TTX and dizolcipine (MK801 ) onto patches excised from these neurons produced large glutamate-activated currents (GACs) that decayed with a single or double exponential time course despite the continued presence of agonist. These desensitization rates of $\alpha$-amino-3-hydroxy-5-methyl-4-isoxazolepropionic acid (AMPA)/kainate-sensitive receptors differed markedly between patches obtained from the two cell types. The fast time constant of desensitization in AHIs $(n=34)$ averaged $3.3 \pm 0.93$ msec (mean \pm SD), while that of SMCs $(n=57)$ averaged $6.8 \pm 2.0 \mathrm{msec}$. Current-voltage relationships of the GACs did not differ between SMCs and AHIs, with comparable reversal potentials and no evidence of inward rectification. We also failed to observe significant $\mathrm{Ca}^{2+}$ permeability in either cell type. However, brief ( $<1 \mathrm{msec}$ ) pulses of $1 \mathrm{~mm}$ glutamate produced rapidly decaying GACs with distinct kinetics in the two neuronal classes. Furthermore, analysis of the single glutamate-activated channel currents in outside-out patches from hilar neurons revealed a larger predominant single-channel current in AHIs versus SMCs. Lastly, we observed a greater sensitivity to cyclothiazide in SMCs versus AHIs, with half-maximal removal of desensitization being $90 \mathrm{~mm}$ and $200 \mathrm{~mm}$, respectively.

Taken together, these differences in GACs between SMCs and AHIs might indicate a functional correlate to the substantial heterogeneity in the molecular structure of giutamate receptor subunits or might be related to posttranslational modifications of these subunits, perhaps provided by the unique microenvironment in the spines covering SMCs.

[Key words: hippocampus, hilus, glutamate, desensitization, AMPA/kainate receptors, dendritic spines]
\end{abstract}

\footnotetext{
Received Apr. 1, 1993; revised June 14, 1993; accepted June 17, 1993.

We thank the late S. M. Schuetze for the curve-fitting computer program; L. Nordholm, Novo Nordisk, Máløv, Denmark, for the gift of NBQX, and Ely Lilly Research Laboratories, Indianapolis, IN, for the gift of cyclothiazide. This work was supported by NINCDS Program Project Grant PO1 NS 28130-01.

Correspondence should be addressed to Dr. Stefano Vicini, F.G.I.N., Georgetown University School of Medicine, 3900 Reservoir Road, N.W., Washington, D.C. 20007.

Copyright (C) 1993 Society for Neuroscience $0270-6474 / 93 / 135324-10 \$ 05.00 / 0$
}

The hilus is a region strategically located in the hippocampal formation between the dentate gyrus and region $\mathrm{CA} 3$, which regulates the flow of excitatory activity (Scharfman et al., 1990; Scharfman, 1991) and has been implicated in the pathogenesis of temporal lobe epilepsy (Sloviter, 1987; Scharfman and Schwartzkroin, 1990) and that deriving from traumatic brain injury (Lowenstein et al., 1992). The hilus contains neurons covered with spines and thorny excrescences, spiny mossy cells (SMCs), and others totally devoid of spines, aspiny hilar interneurons (AHIs). SMCs and somatostatin-immunoreactive AHIs (Bakst et al., 1986; Sloviter and Nilaver, 1987) are particularly vulnerable to cell death, whereas parvalbumin-immunoreactive AHIs are resistant (Sloviter, 1989). The reason for this difference in susceptibility is presently unclear, but could be due, in part, to the differential expression or regulation of non-NMDA receptor subtypes.

Intense and continuous spontaneous excitatory synaptic activity has been reported in both AHIs and SMCs (Scharfman et al., 1990; Scharfman, 1991; Livsey and Vicini, 1992). There is a difference in the kinetics of spontaneous excitatory postsynaptic currents (sEPSCs) between AHIs and SMCs in the hippocampal hilus (Livsey and Vicini, 1992). sEPSC's in AHIs ( $n$ $=48$ ) are much faster (mean rise time $=0.5 \pm 0.2 \mathrm{msec}$, mean decay time constant $=3.6 \pm 1.5 \mathrm{mscc}$, mcan $\pm \mathrm{SD}$ ) than those in SMCs $(n=55$, mean rise time $=1.0 \pm 0.3 \mathrm{msec}$, mean decay time constant $=9.6 \pm 4.8 \mathrm{msec}$; Livsey and Vicini, 1992). These differences did not result simply from dendritic filtering (Livsey and Vicini, 1992), but were more likely a consequence of functionally different non-NMDA receptors or spine filtering.

The differences in synaptic strength we observed could be achieved through the differential expression or regulation of non-NMDA receptors in the different cell types since multiple AMPA/kainate receptor subunits have recently been cloned (Hollmann et al., 1989; Bettler et al., 1990, 1992; Boulter et al., 1990; Keinanen et al., 1990; Sommer et al., 1990; Egebjerg et al., 1991; Werner et al., 1991) and differences in AMPA/kainate receptor subunit distribution can now be revealed with specific antibodies (Blackstone et al., 1992a,b; Wenthold et al., 1992). Furthermore, important functional differences between specific AMPA/kainatc receptor subtypes have been demonstrated, including desensitization rate, agonist sensitivity, relative $\mathrm{Ca}^{2+}$ permeability, and rectification properties (Sommer et al., 1990; Hume et al., 1991; Verdoorn et al., 1991; Burnashev et al., 1992; Herb et al., 1992; Egebjerg and Heinemann, 1993).

Unlike at the neuromuscular junction, where nicotinic $\mathrm{ACh}$ receptors respond to a very brief exposure of neurotransmitter (which is rapidly hydrolyzed) with a very rapid activation and 
opening of channels followed by a rapid exponential decay that reflects the mean open time of the receptor-ionophore complex (Magleby and Stevens, 1972), the biophysical properties of fast synaptic transmission in the CNS are not fully defined. Glutamate is not rapidly degraded and will remain in the synaptic cleft until it is cleared by diffusion. Prolonged application of glutamate induces non-NMDA receptors to desensitize rapidly (Tang et al., 1989, 1991; Trussell and Fischbach, 1989; Jonas and Sakmann, 1992; Colquhoun et al., 1992), suggesting that desensitization may contribute to synaptic decay. However, it has been estimated by Eccles and Jaeger (1958) for central synapses that because of diffusion only $10 \%$ of the peak neurotransmitter concentration remains after $500 \mathrm{msec}$, and a more recent study (Clements et al., 1992) suggests that 1 mm glutamate might be cleared from the synaptic cleft with a time constant of about $1.2 \mathrm{msec}$. In fact, by studying the action of brief pulses of glutamate on AMPA/kainate receptors in patches excised from different neurones in rat brain slices, it has been demonstrated that deactivation of the AMPA receptor occurs more rapidly than desensitization (Hestrin, 1992; Colquhoun et al., 1992). These results imply that desensitization will not contribute significantly to the decay of the synaptic current. Yet other studies using agents that remove desensitization do, in fact, affect synaptic current decay times (Ito et al., 1990; Isaacson and Nicoll, 1991; Tang et al., 1991; Vyklicky et al., 1991; Patneau et al., 1992; Yamada, 1992; Yamada and Rothman, 1993). However, it has been pointed out that drugs that remove desensitization might do so either by decreasing the desensitization rate constant or by decreasing the channel closing rate constant (Vyklicky et al., 1991).

Therefore, we have investigated glutamate-activated currents (GACs) in outside-out patches, using a rapid perfusion system based on a piezoelectric translator to apply both prolonged steps (50-100 msec) and very short pulses (0.1-1 msec) of L-glutamate measured according to Lester and Jahr (1992). The step application was used to determine desensitization rates of non-NMDA receptors, whereas the pulse was employed to mimic transmission at excitatory synapses. Current-voltage relationships and $\mathrm{Ca}^{2+}$ permeability of the non-NMDA receptors were investigated in the patches from AHIs and SMCs since differences in these properties would suggest receptor heterogeneity. Singlechannel currents were also investigated in the patches since channel conductance is most likely an intrinsic property of the molecular structure of the non-NMDA receptor subunits present. Finally, sensitivity of the currents to cyclothiazide, an agent shown to remove non-NMDA receptor desensitization (Patneau et al., 1992; Yamada, 1992; Zorumski et al., 1993), was also investigated.

\section{Materials and Methods}

Brain slices. Slices of hippocampus (200-300 $\mu \mathrm{m}$ ) were prepared from 14-28 d postnatal Sprague-Dawley rats as described by Edwards et al. (1989). Hilar neurons were viewed with an upright microscope equipped with Nomarski optics (UEM, Zeiss, Germany). Superficial cells were used to minimize the series resistance (typically $<10 \mathrm{M} \Omega$ ).

Solutions and drugs. Experiments were performed at room temperature $\left(22-24^{\circ} \mathrm{C}\right)$ using an oxygenated extracellular medium composed of (mM) $\mathrm{NaCl}(120), \mathrm{KCl}(3.1), \mathrm{K}_{2} \mathrm{HPO}_{4}$ (1.25), $\mathrm{NaHCO}_{3}$ (26), dextrose (5.0), $\mathrm{MgCl}_{2}(1.0)$, and $\mathrm{CaCl}_{2}(2.0)$, maintained at $\mathrm{pH} 7.4$ with $5 \% \mathrm{CO}_{2}$, $95 \% \mathrm{O}_{2}$. The high-Ca ${ }^{2+}$ solution consisted of (mM) $\mathrm{CaCl}_{2}(110)$ and HEPES [5, pH 7.4 with $\left.\mathrm{Ca}(\mathrm{OH})_{2}\right]$. The slice was completely submerged in a total volume of $500 \mu \mathrm{l}$ and continuously perfused at a rate of $5 \mathrm{ml} /$ min. Tetrodotoxin (TTX; Sigma, St. Louis, MO) and 2,3-dihydroxy-6nitro-7-sulfamoyl-benzo(F)quinoxaline (NBQX; a gift of Dr. L. Nor- dholm, Novo Nordisk, Máløv, Denmark) were dissolved in water and diluted in extracellular medium; dizolcipine (MK-801; Research Biochemicals, Inc., Natick, MA) and 3-bicyclo[2.2.1] hept-5-en-2-yl-6-chloro-3,4-dihydro-2H-1,2,4-benzothiadiazine-7-sulfonamide 1,1-dioxide (cyclothiazide; a gift of Ely Lilly Research Laboratories, Indianapolis, IN) were initially dissolved in dimethylsulfoxide (final concentration < $0.1 \%$ in extracellular medium). A piezoelectric translator-based fast drug application system (P-245.30 Stacked Translator, Physik Instrumente, Waldbronn, Germany) was used to apply glutamate rapidly, with and without cyclothiazide, as well as glutamate in solutions with $\mathrm{Na}^{+}$ or $\mathrm{Ca}^{2+}$ as major current carrier to outside-out membrane patches. Multiple drugs and doses of drugs were tested using four-barreled square glass (Vitro Dynamics, Rockway, NJ) pipettes. After each patch recording, on and off rates as well as pulse duration were mcasurcd by "blowing out" the patch and recording currents generated by the liquid junction potential due to a 50:1 dilution of the glutamate-containing solution (Lester and Jahr, 1992). On and off rates of the system were typically less than $0.2 \mathrm{msec}$.

Whole-cell recordings. The single-electrode tight-seal technique was used in the whole-cell and outside-out patch recording configurations (Hamill et al., 1981). Electrodes were pulled in two stages on a vertical pipette puller from borosilicate glass capillaries (pipette resistance, 2-7 $\mathrm{M} \Omega$ ). Intracellular (pipette) solutions contained (mM) K-gluconate (145) or Cs-methylsulfonate (145), $\mathrm{MgCl}_{2}$ (1), 1,1 ethyleneglycol-bis- $(\beta$-aminoethylether)- $N, N, N^{\prime}, N^{\prime}$-tetraacetic acid (EGTA) (5.0), ATP (2.0), and HEPES (10) to pH 7.2 with $\mathrm{KOH}$ or $\mathrm{CsOH}$. To stain recorded cells fluorescently, Lucifer yellow CH (Sigma) was diluted in the pipette solution to a final concentration of $4 \mathrm{mg} / \mathrm{ml}$. Effective diffusion of the intracellular solution into the cell occurs in 1-3 min, as evaluated by the lengthening of the action potential (AP) duration measured at the threshold. Thus, AP characteristics were measured immediately (within $1 \mathrm{~min}$ and prior to measurable AP lengthening) upon rupturing the cell membrane by injecting depolarizing current pulses. Whole-cell recordings were performed in current and voltage clamp with a patch-clamp amplifier (EPC 7, List Electronics, Dornstadt, Germany) after capacitance and series resistance compensation. Series resistance was checked for constancy throughout the experiments. Whole-cell current and voltage traces were recorded on a VR-10 data storage system (Instrutech Co., Haverhill, MA).

Data analysis. Whole-cell current traces were filtered at $3 \mathrm{kHz}(-3$ $\mathrm{dB}, 8$-pole, low-pass Bessel filter, Frequency Devices) and stored in an LSI $11 / 73$ computer (INDEC System, Sunnyvale, CA) after digitization $(10 \mathrm{kHz})$ with a Data Translation analog-to-digital converter. Decay time constants of EPSCs were determined from exponential fitting with an entirely automated least-squares procedure. This method uses a Simplex algorithm (Caceci and Cacheris, 1984) to fit the data to either a single or double exponential equation of the form $I(t)=I_{f} \exp \left(-t / \tau_{f}\right)$ $+I_{s} \exp \left(-t / \tau_{s}\right)$, where $t$ is time, $I_{f}$ and $I_{s}$ are the amplitudes of the currents' fast and slow components, and $\tau_{f}$ and $\tau_{s}$ are their respective decay time constants. Peak amplitudes are measured at the absolute maximum of the EPSCs, taking into account the noise of the baseline and noise around the peak. Rise times represent the time elapsed from $20 \%$ to $80 \%$ of the peak amplitude of the response.

Outside-out patch glutamate-activated currents (GACs) were recorded on the VCR-based data storage system. For fast application of excitatory amino acid agonists at high desensitizing concentrations, data were treated as for whole-cell recording of synaptic currents and single or double exponential fittings performed. For single-channel current analysis of individual channel properties, prolonged application of glutamate $(20 \mu \mathrm{M})$ in the presence of cyclothiazide $(50 \mu \mathrm{M})$ was used. Digital acquisition was performed at a sampling rate of $10 \mathrm{kHz}$. Individual channel openings were detected and measured by eye with a semiautomated procedure (see Jaramillo and Schuetze, 1988, for further details).

Statistics. Results are expressed as mean \pm SD. Student's $t$ test for grouped data was employed; $p<0.05$ was considered as an indication of statistical significance.

\section{Results}

The hilus contains neurons covered with spines and thorny excrescences, spiny mossy cells (SMCs), and others totally devoid of spines, aspiny hilar interneurons (AHIs), both of which receive excitatory synaptic input from en passant mossy fibers (Amaral, 1978; Ribak and Seress, 1983; Ribak et al., 1985). 
Table 1. A comparison of the kinetics of sEPSCs and GACs in hilar neurons

\begin{tabular}{llllllll} 
& $\tau_{\text {epsc }}(\mathrm{msec})$ & $\tau_{\text {pulse }}(\mathrm{msec})$ & $\tau_{\text {fstep }}(\mathrm{msec})$ & $\tau_{\text {sslep }}(\mathrm{msec})$ & $\%$ Slow & $\mathrm{Rt}_{\text {cpsc }}$ (msec) & $\mathrm{Rt}_{\mathrm{GAC}}(\mathrm{msec})$ \\
\hline $\mathrm{AHI}$ & $3.4 \pm 0.9$ & $2.1 \pm 0.7$ & $3.3 \pm 0.93$ & $20 \pm 10$ & $15 \pm 12$ & $0.4 \pm 0.2$ & $0.4 \pm 0.1$ \\
$\mathrm{SMC}$ & $9.3 \pm 3.4$ & $4.3 \pm 2.3$ & $6.8 \pm 2.0$ & $32 \pm 20$ & $44 \pm 25$ & $0.9 \pm 0.3$ & $0.8 \pm 0.5$
\end{tabular}

Decay time constants $(\tau)$ determined from single or double exponential fitting are compared for EPSCs $\left(\tau_{c p s}\right)$ GACs elicited by pulses $(1 \mathrm{~mm},<1 \mathrm{msec})$ of glutamate $\left(\tau_{\text {oulsc }}\right)$, and GACs evoked by steps $(1 \mathrm{~mm}, 50 \mathrm{msec})$ of glutamate $\left(\tau_{\text {fstep }}\right.$ ) $\tau_{\text {sstep }}, \%$ Slow). Rt indicates the rise time for each current. Peak amplitudes of GACs were highly variable (range of $20-$ $900 \mathrm{pA}$ in both cell types). Values are expressed as mean \pm SD and are derived from 57 SMCs and 34 AHIs for sEPSCs and step experiments and from $27 \mathrm{SMCs}$ and $15 \mathrm{AHIs}$ for pulse experiments.

Neurons were identified as previously described (Scharfman and Schwartzkroin, 1988; Scharfman et al., 1990; Livsey and Vicini, 1992). Briefly, depolarizing current injection through the recording pipette revealed two types of hilar neurons with specific identifying AP characteristics. AHIs displayed a pattern of a fast rising depolarization and APs followed by large afterhyperpolarizations, whereas SMCs showed a slower rising depolarization, and APs were followed by only slight afterpolarizations. All neurons were filled with Lucifer yellow and examined for the presence or absence of somatic and/or dendritic spines following each recording.

\section{SEPSCs and GACs in characterized hilar neurons}

sEPSCs were recorded in the whole-cell configuration (holding potential, $\mathrm{HP}=-70 \mathrm{mV}$ ) before removing an outside-out patch for examining GACs. Both sEPSC decay and GAC desensitization rates were slower in SMCs versus AHIs. The decay times of the sEPSCs were well fit with a single exponential function (Fig. 1A). For the synaptic currents from the AHI shown (50 events averaged), the mean rise time was $0.3 \mathrm{msec}$, and the decay time constant was $2.1 \mathrm{msec}$. The corresponding values for the SMC currents in this figure were 0.6 and $8.5 \mathrm{msec}$,
Figure 1. Desensitization of GACs is faster in AHIs than in SMCs. $A$, sEPSCs were observed in the whole-cell recording configuration $(\mathrm{HP}=-70 \mathrm{mV})$. The decay times of these currents were well fit with a single exponential function. In this $\mathrm{AHI}$, the mean rise time of the currents (50 events averaged) was 0.3 msec, and the decay time constant was $2.1 \mathrm{msec}$. The corresponding values for the SMC were 0.8 and $8.5 \mathrm{msec}$, respectively. $B$, Glutamate ( $1 \mathrm{~mm})$, in addition to MK-801 (50 $\mu \mathrm{M})$ and TTX (1 $\mu \mathrm{M})$, was rapidly applied $(<0.1 \mathrm{msec}$ onset) to outside-out patches $(\mathrm{HP}=-70$ $\mathrm{mV}$ ) from the above neurons for a total duration of about $50 \mathrm{msec}$. In the continuous presence of glutamate, the majority of non-NMDA receptors rapidly desensitized, leaving only a small plateau of current until the end of the application. $C$, The desensitization rates were determined from an average of five of the above GACs by fitting the decay with either a single or double exponential function. In the AHI shown, a single exponential function with a time constant of $3.8 \mathrm{msec}$ accurately fit the decay. In the patch from the SMC, the desensitization rate was best fit by the sum of two exponentials with time constants of 9.8 and $33 \mathrm{msec}$, respectively (20\% slow component). A second component was often present in AHIs as wcll (not shown here).

\section{A}

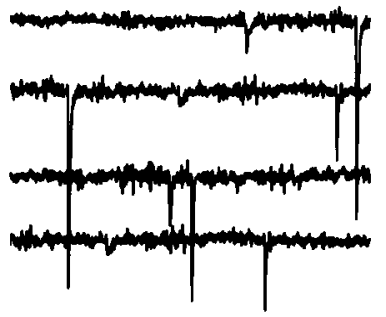

$\mathrm{AHI}$

EPSCs

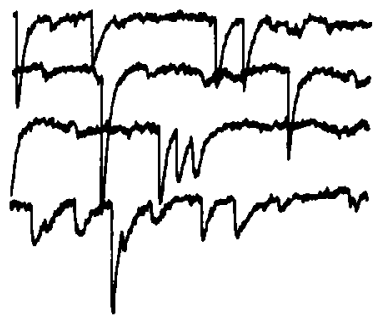

SMC

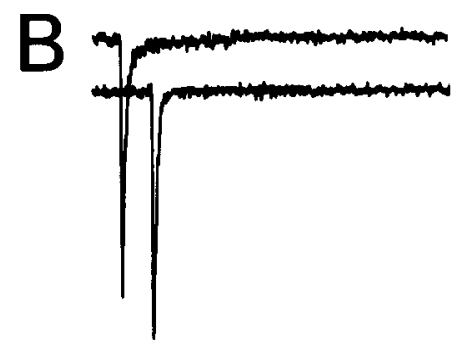

PATCH

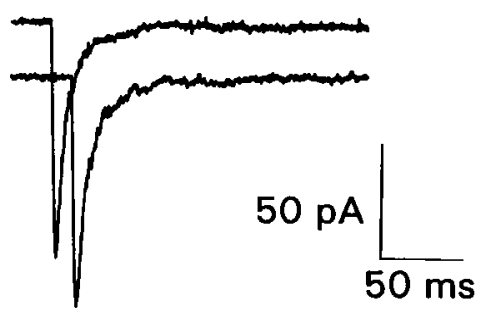

\section{EXPONENTIAL FITTING}

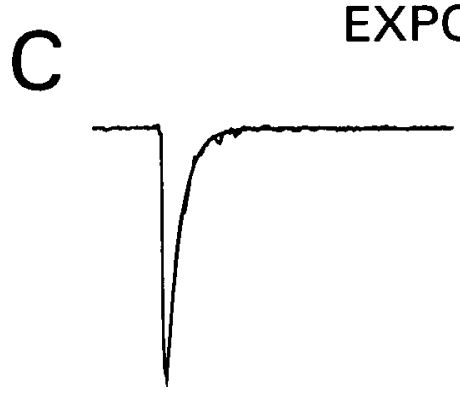

$\mathrm{Vh}-70 \mathrm{mV}$

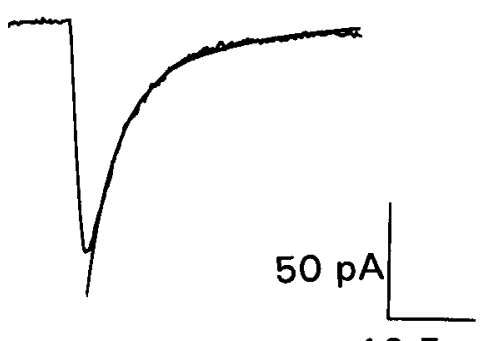

$12.5 \mathrm{~ms}$ 


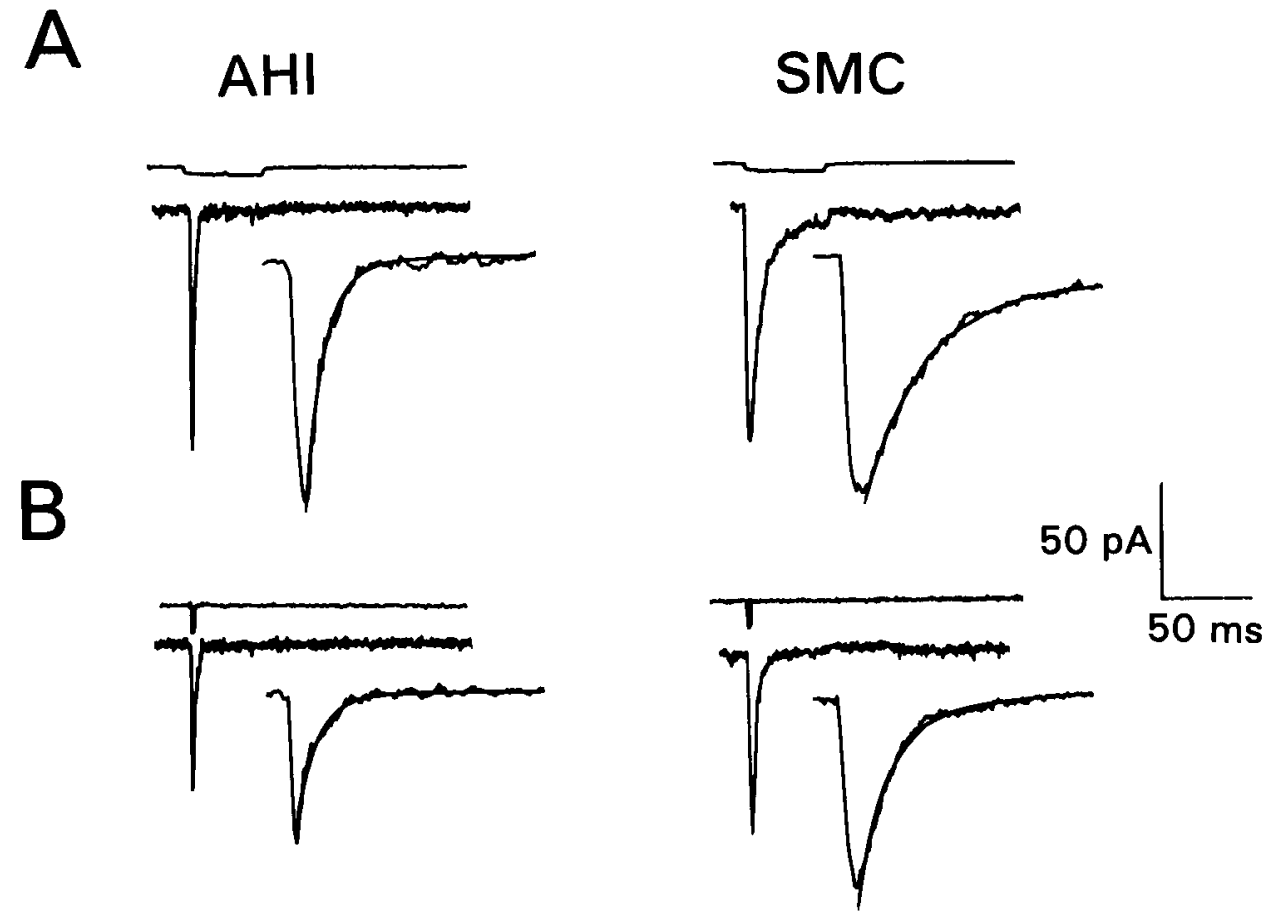

Figure 2. Differences between GACs produced by short pulse and long step applications of glutamate in hilar neurons. Glutamate pulse duration affected the decay rates of the GACs in outsideout patches. Patches were held at -70 $\mathrm{mV}$ while glutamate was rapidly applied ( $<0.2 \mathrm{msec}$ onset) for either long steps $(50-100 \mathrm{msec})$ or short pulses $(<1$ $\mathrm{msec}$ ). Application duration was measured following each experiment by observing the currents produced by the changes in the liquid junction potential (glutamate solution diluted with water 50:1) after blowing out the patch and is shown above each trace. $A$, Prolonged glutamate (1 mM) steps resulted in GACs that were clearly distinguishable in patches from AHIs versus SMCs. The decay rate in the AHI shown was 3.6 msec, while the decay rate consisted of two components of 8.7 and $45 \mathrm{msec}$ in the SMC, as a result of the exponential fitting shown superimposed on the raw data in a threefold expanded time scale in the lower insets. $B$, In the same patches, short-duration pulses of glutamate $(1 \mathrm{~mm})$ resulted in GACs that decayed more rapidly in both cell types. The decay time constants in the neurons shown were $2.9 \mathrm{msec}$ and $4.9 \mathrm{msec}$ for the AHI and SMC, respectively (lower insets). respectively. In outside-out patch recordings (Fig. $1 B, C ; \mathrm{HP}=$ $-70 \mathrm{mV}$ ), the majority of non-NMDA receptors rapidly desensitized following a rapid ( $<0.2 \mathrm{msec}$ onset) $1 \mathrm{mM} \mathrm{L-glutamate}$ concentration jump (in the presence of $50 \mu \mathrm{M} \mathrm{MK}-801$ and 1 $\mu \mathrm{M}$ TTX), leaving only a small plateau of current until the end of the step application (approximately $50 \mathrm{msec}$ total duration). These GACs were completely blocked by $5 \mu \mathrm{M}$ NBQX (7 AHIs, 12 SMCs; Sheardown et al., 1990), demonstrating that NMDA receptors did not, in fact, contribute to either the desensitizing or the plateau phase. The desensitization rates were determined from an average of five GACs by fitting the decay with either a single or double exponential function (Fig. 1C). In the AHI shown, a single exponential function with a time constant of $3.8 \mathrm{msec}$ accurately fit the decay. In the patch from the SMC, the desensitization rate was best fit by the sum of two exponentials with time constants of 9.8 and $33 \mathrm{msec}$, respectively ( $20 \%$ slow component). A second component was usually present in AHIs as well. Overall, the fast time constant in AHIs ( $n$ $=34$ ) averaged $3.3 \pm 0.93 \mathrm{msec}$; slow, $20.8 \pm 10.5 \mathrm{msec}$; and percentage slow, $14.9 \pm 12.3 \%$ (Table 1). In four of these neurons, no slow component $(0 \%)$ was present. In SMCs, $(n=57)$ the fast component averaged $6.8 \pm 2.0 \mathrm{msec}$; slow, $32.1 \pm 20.0$ msec; and percentage slow, $43.8 \pm 25 \%$ (Table 1 ). Higher concentrations of glutamate (up to $5 \mathrm{~mm}$ ) increased the amplitude of the responses without obviously affecting the decay rates in both cell types $(n=5)$.

\section{GACs produced by step and pulse glutamate application in distinct hilar neurons}

Differences in desensitization rates demonstrate a biophysical difference in the non-NMDA receptors in AHIs versus SMCs, yet the physiological relevance of this difference is unclear since thcre is growing evidence that desensitization does not contrib- ute to synaptic current decay (Clements et al., 1992; Hestrin, 1992; Colquhoun et al., 1992). Thus, the effect of changing glutamate pulse duration on GAC decay rate was examined in outside-out patches voltage clamped at $-70 \mathrm{mV}$. Prolonged (50 $\mathrm{msec}$ ) glutamate concentration steps ( $0-1 \mathrm{~mm})$ resulted in GACs that were clearly distinguishable in patches from AHIs versus SMCs (Fig. 2A). The decay rate in the AHI shown was $3.6 \mathrm{msec}$, while the decay rate consisted of two components of 8.7 and 45 msec in the SMC. Step duration is shown above each trace. In an attcmpt to mimic synaptic transmission in the same patches (Fig. 2B), glutamate (1 mM) was applied for brief periods (glutamate pulses), less than $1 \mathrm{msec}$ as measured at the end of the recording after blowing out the patch (see Materials and Methods and Lester and Jahr, 1992). GACs in response to glutamate pulses decayed rapidly in both neuronal types. However, the decay time constants of SMCs were, on average, about twofold slower than those in AHIs, being $2.1 \pm 0.7(n=15)$ and $4.3 \pm$ $2.3(n=27)$, respectively (Table 1$)$. It is worth noting that GACs in patches from some SMCs decayed as rapidly as those in AHIs.

Similar and distinct properties of GACs from AHIS and SMCs Non-NMDA receptors lacking the GluR-B subunit exhibit strong inward rectification of the current-voltage $(I-V)$ relationship (Hume et al., 1991; Verdoorn et al., 1991; Burnashev et al., 1992), and recombinant receptors containing other subunits have also been shown to produce nonlinear $I-V$ relationships (Egebjerg and Heinemann, 1993). Thus, desensitizing glutamate currents were examined in patches voltage clamped at various negative and positive HPs (Fig. 3). The maximum current observed near the beginning of the step application (peak) and the current amplitude at the end of the $50 \mathrm{msec}$ step (plateau) of the GACs linearly decreased as the membrane patch was depolarized, inverted between 0 and $+20 \mathrm{mV}$, and linearly increased at positive 


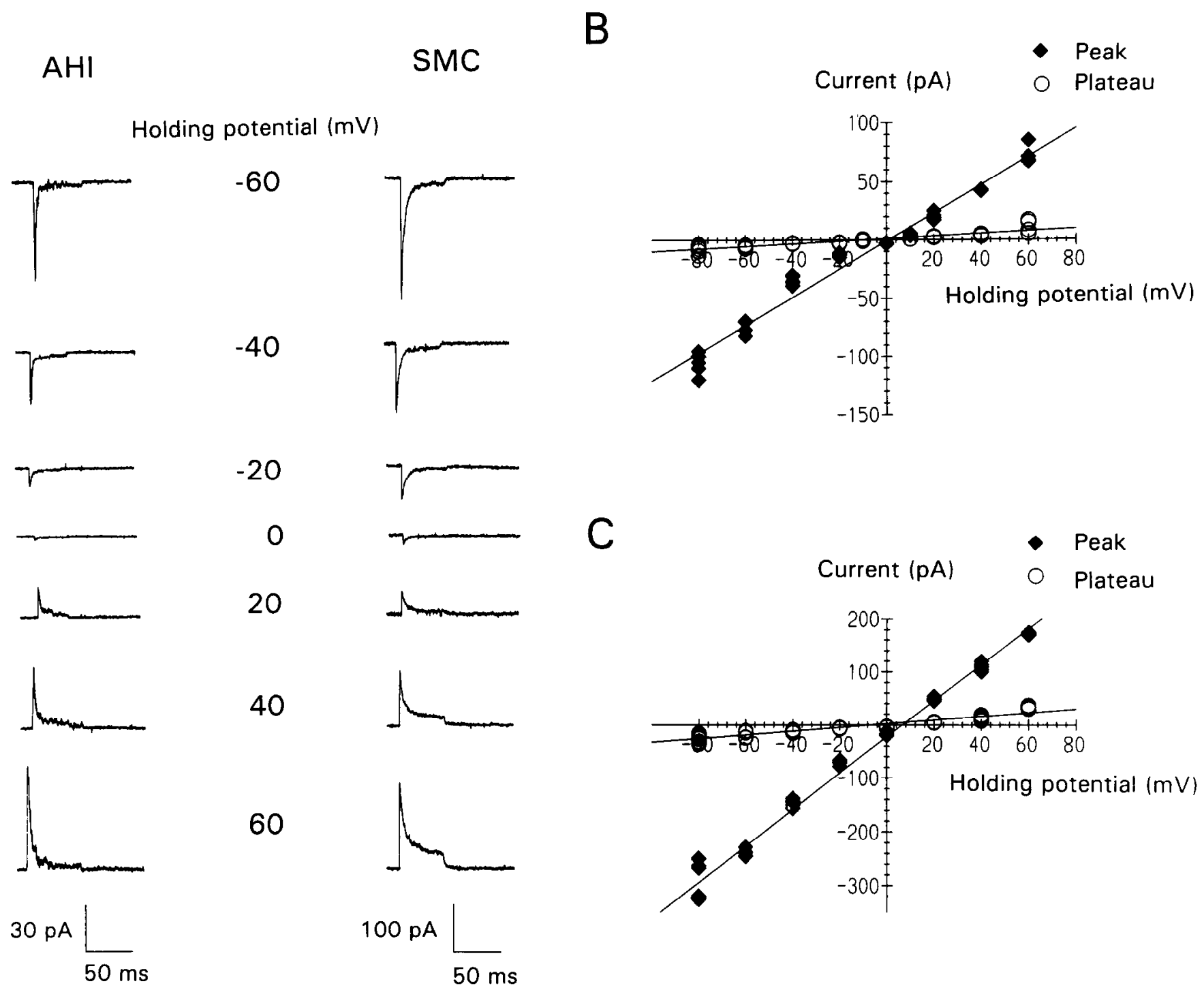

Figure 3. Current-voltage relationship in hilar neurons. A, Desensitizing glutamate currents were observed in patches held at various negative and positive HPs. Glutamate was rapidly applied ( $<0.2 \mathrm{msec}$ rise time) for $50 \mathrm{msec}$, several times at each HP. The single traces demonstrate that both peak and plateau (the current amplitude at the end of the step) decreased as the membrane patch was depolarized, and both reverted between 0 and $20 \mathrm{mV}$ in both cell types. However, a precise measurement of the reversal potential for the plateaus of the GACs was hampered by its small size. $B$. The current-voltage $(I-V)$ plot of the peak and plateau phases of the currents from the AHI demonstrates the linearity and the reversal potential of $2.2 \mathrm{mV}$ for the peak and $4.1 \mathrm{mV}$ for the plateau. On average, the peak of GACs from AHIs reverted at $6.1 \pm 3.1 \mathrm{mV}(n=7)$. $C$, The $I-V$ plots from the SMC also demonstrated linearity, and the reversal potentials in this cell were 6.3 and $0.3 \mathrm{mV}$, peak and plateau, respectively. On average, GACs reverted at $8.1 \pm 2.0 \mathrm{mV}$ in patches from SMCs $(n=7)$.

HPs in both cell types. On average, the reversal potential for the peak of GACs from AHIs was $6.1 \pm 3.1 \mathrm{mV}(n=7)$ while that from SMCs was $8.1 \pm 2.0 \mathrm{mV}(n=7)$.

$\mathrm{Ca}^{2+}$ permeability of non-NMDA receptors also depends on the presence or absence of the edited GluR-B subunit (Hume et al., 1991; Verdoorn et al., 1991; Burnashev ct al., 1992; Egebjerg and Heinemann, 1993). The lack of inward rectification in the two neuronal populations would suggest low $\mathrm{Ca}^{2+}$ permeability. In fact, in patches from AHIs $(n=3)$ and SMCs $(n=4)$, glutamate $(1 \mathrm{mM})$ dissolved in the normal extracellular medium produced large desensitizing GACs $(\mathrm{HP}=-70 \mathrm{mV})$, whereas in the same patches, after properly positioning the rapid application pipette by voltage clamping the cell at a positive HP to observe a current carried by $\mathrm{Cs}^{+}$(see Burnashev et al., $1992)$, glutamate $(1 \mathrm{mM})$ in a high $\mathrm{Ca}^{2+}(110 \mathrm{~mm}) / 0 \mathrm{Na}^{+}$solution failed to produce measurable currents when the cell was voltage clamped at $-70 \mathrm{mV}$ (Fig. 4).

To look further for differences in non-NMDA receptor subunits expressed in the two neuronal subtypes, single-channel properties were examined in outside-out patches. Single channels were activated either by applying low concentrations of glutamate $(20 \mu \mathrm{M}$ in the presence of cyclothiazide $(50 \mu \mathrm{M})$ to prevent desensitization (Fig. $5 A$ ), or by rapidly applying a higher concentration of glutamate $(1 \mathrm{mM})$ as described previously with a slight modification (Fig. 5B,C). During these step applications, the control solution was turned off to allow glutamate to reperfuse the patch randomly, producing a "tail" of single-channel openings. The latter method was used to ensure that the channel openings observed during the rapid phase of GAC decay (and assumed to be those activated during synaptic transmission) 
A

$\mathrm{AHI}$

SMC

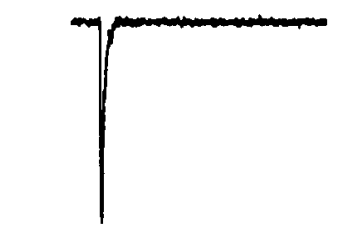

$140 \mathrm{mM} \mathrm{Na}^{+}$

$2 \mathrm{mM} \mathrm{Ca}^{2+}$

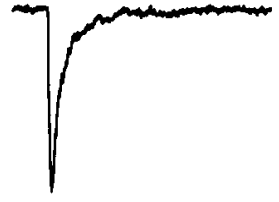

B

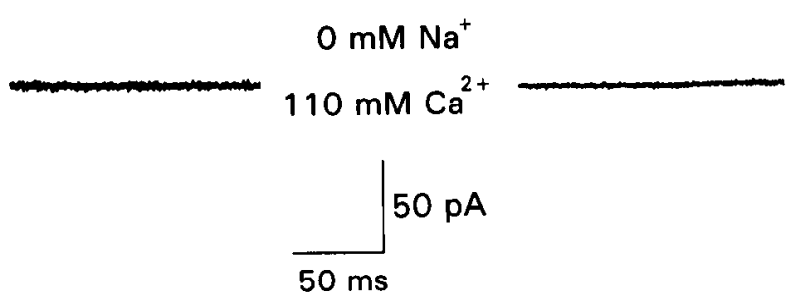

Figure 4. Non-NMDA receptor channels are not $\mathrm{Ca}^{2+}$ permeable in hilar neurons. $\mathrm{Ca}^{21}$ permeability of non-NMDA receptors in patches from hilar neurons has been examined using the piezoelectric translator and four-barreled square glass, with two lanes containing control and glutamate $(1 \mathrm{~mm})$ in normal extracellular medium and the other two lanes containing control and glutamate $(1 \mathrm{~mm})$ in a high-Ca ${ }^{2+}(110 \mathrm{~mm}) /$ $0 \mathrm{Na}^{+}$solution. $A$, Glutamate in normal extracellular medium was rapidly applied to outside-out patches voltage clamped at $-70 \mathrm{mV}$ to produce the current shown; the HP was then shifted to positive values to enable positioning for the response in the presence of $\mathrm{Ca}^{2+}$ (intracellular solution contained $\mathrm{Cs}^{+}$methylsulfonate). $B$, After positioning the pipette, the patch was held again at $-70 \mathrm{mV}$ to observe the GACs in the presence of $\mathrm{Ca}^{2+}$. In all AHIs $(n=3)$ and SMCs $(n=4)$ testcd, minimal or no $\mathrm{Ca}^{2+}$ permeability was observed.

were the same as those activated with the prolonged application of a lower concentration of glutamate plus cyclothiazide. In fact, single-channel currents were of similar amplitude using either method in any given membrane patch.

Single-channel currents measured at $-70 \mathrm{mV}$ HP differed between hilar cell types. Although openings at several current levels were present in most patches, the most frequently occurring single-channel currents in AHIs were always larger than those in SMCs. Non-NMDA receptor channels in excised patches from AHIs $(n=12)$ typically had a predominant current opening level of $3.3 \pm 0.22 \mathrm{pA}$, although openings at different levels were observed, whereas channels in patches from SMCs ( $n=26$ ) often had two main current levels of $1.1 \pm 0.17$ and $2.4 \pm 0.29 \mathrm{pA}$, although four membrane patches lacked the lower level. In some neurons, slope conductances were determined from the single-channel currents observed at three or more HPs, and those values were also significantly different between cell types being $50 \pm 7.4 \mathrm{pS}$ in AHIs $(n=5)$ and 15 \pm 3.1 and $33 \pm 3.9 \mathrm{pS}$, in SMCs $(n=7)$.

\section{Cyclothiazide effects on GACs from AHIs and SMCs}

Cyclothiazide has been shown to modulate non-NMDA receptor ionophore complexes by removing desensitization (Patneau et al., 1992; Yamada, 1992; Zorumski et al., 1993). To determine if non-NMDA receptors in AHIs versus SMCs are differentially sensitive to this agent, L-glutamate $(1 \mathrm{mM})$ was rapidly applied in the absence or presence of cyclothiazide $(100 \mu \mathrm{M})$ with the piezoelectric translator and the four-barrel square capillary glass system. GACs desensitized rapidly in control con-
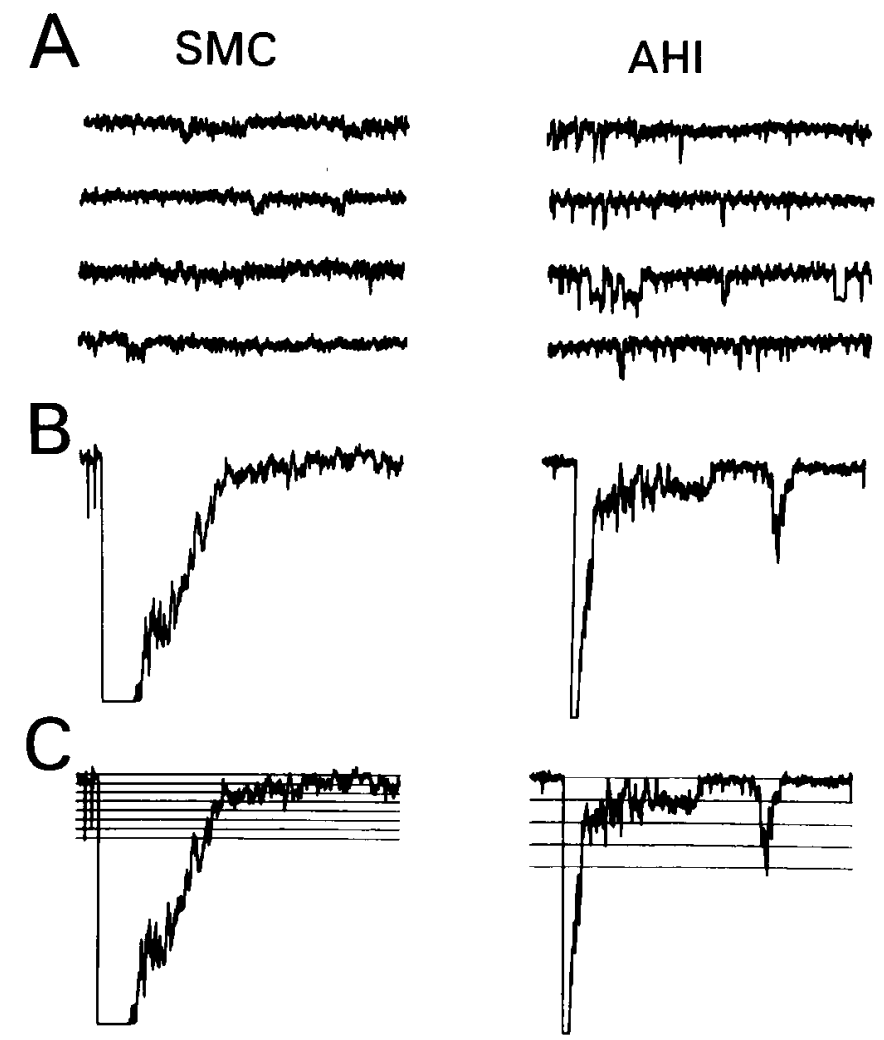

$10 \mathrm{pA} \frac{}{30 \mathrm{~ms}}$

Figure 5. Non-NMDA receptor single-channel currents differ between AHIs and SMCs. Singlc-channcl currents of non-NMDA receptor-ionophore complexes measured at similar HPs differed in outside-out patches from AHIs versus SMCs. Although several opening levels were present in most patches from hilar neurons, the most frequently occurring singlechannel currents in AHIs were always larger than those in SMCs. $A$, Glutamate $(20 \mu \mathrm{M})$ applied to patches $(\mathrm{HP}=-70 \mathrm{mV})$, in the presence of cyclothiazide $(50 \mu \mathrm{M})$ to prevent desensitization, resulted in several openings of non-NMDA receptor channels. The predominant singlechannel currents observed were $2.0 \mathrm{pA}$ for the SMC and $3.4 \mathrm{pA}$ for the AHI shown. $B$, An enlarged view of a higher concentration of glutamate (1 $\mathrm{mm}$ ) rapidly applied to the same patches. During these brief applications, the control solution was turned off to allow glutamate to reperfuse the patch randomly, producing a "tail" of single-channel openings. $C$, Vectors were placed by eye to identify the single-channel openings in the above traces, using as a guideline the channel current amplitudes obtained in $A$.

ditions (Fig. 6A), but this desensitization was almost completely removed by $100 \mu \mathrm{M}$ cyclothiazide in SMCs, while it was only partially removed by the same concentration of the agent in AHIs (Fig. 6B). A partial dose-response study (Fig. 6C) of the percentage plateau/peak response demonstrates a differential sensitivity to cyclothiazide in hilar neurons (at least four patches were examined per each concentration). The plateau phase for a $100 \mathrm{msec}$ step was larger in control conditions in patches from SMCs versus AHIs, being $7.1 \pm 2.0$ for AHIs $(N=10)$ and 18.1 \pm 7.4 for SMCs $(N=38)$, and became progressively larger with increasing concentrations of cyclothiazide. At $100 \mu \mathrm{M}$ the response was almost saturated in SMCs but less than half in AHIs. Saturation of the response in the AHIs was not reached until at least $400 \mu \mathrm{M}$ cyclothiazide. Half-maximal removal of desensitization was $90 \mu \mathrm{M}$ for SMCs and $200 \mu \mathrm{M}$ for AHIs. 
A

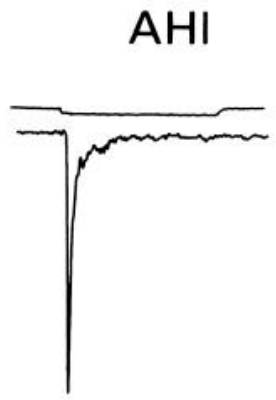

SMC

B

+ CYCLOTHIAZIDE $100 \mu \mathrm{M}$
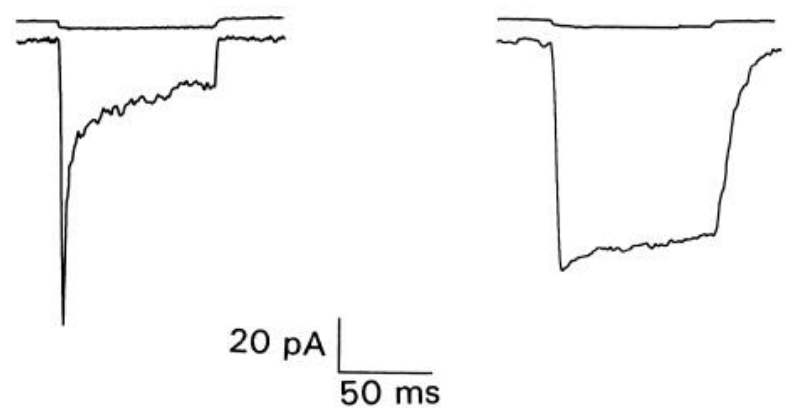

C

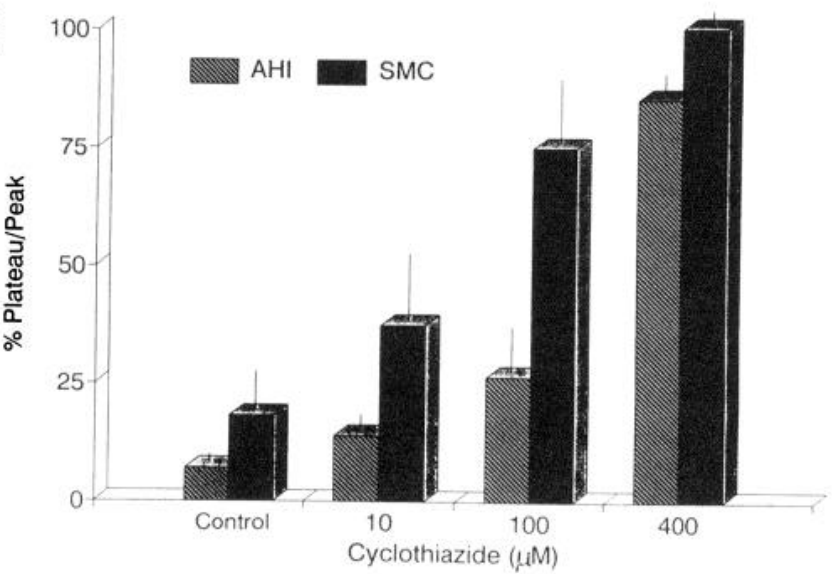

Figure 6. Cyclothiazide differentially affects GACs in AHIs and SMCs. We demonstrate here that the non-NMDA receptors in AHIs versus SMCs are differentially sensitive to this agent. $A$ and $B$, Glutamate (1 mM) was rapidly applied in the absence $(A)$ or presence $(B)$ of cyclothiazide $(100 \mu \mathrm{M})$ with the piezoelectric translator and four-barrel square capillary glass system. The average of 5-10 GACs is shown in each trace. GACs desensitized rapidly in control conditions $(A)$, but this desensitization was partially removed by $100 \mu \mathrm{M}$ cyclothiazide in AHIs and almost completely removed by the same concentration of the agent in SMCs $(B)$. $C$, A partial dose-response analysis of the percentage plateau/peak response reveals this differential sensitivity to cyclothiazide (at least four patches were examined per each concentration). The plateau phase was larger in control conditions in patches from SMCs versus AHIs and became progressively larger with increasing concentrations of cyclothiazide. At $100 \mu \mathrm{M}$ the response was almost saturated in SMCs but less than half in AHIs. Saturation of the response in the AHIs was not reached until at least $400 \mu \mathrm{M}$ cyclothiazide.

\section{Discussion}

The trisynaptic circuit in the hippocampus, connecting granule cells with pyramidal cells of areas CA 3 and CA1, is finely regulated via neurons in the hilus, the anatomical region bordered by the dentate gyrus and the beginning of the CA3 layer. Pathological changes following hippocampal damage have been shown to produce selective loss of hilar SMCs as well as somatostatinimmunoreactive aspiny interneurons, a subclass of AHIs. This phenomenon has resulted in the "dormant basket cell" hypothesis (Sloviter, 1987), which implies a role for the loss of hilar neurons in the pathophysiology and pathology of the epileptic state. Inhibitory, GABA-containing basket cells normally plays an important role in the feedback control of hippocampal activity. It has been proposed, but the experimental evidence is still missing, that hilar neurons form a basket cell-activating system, and their loss may be the cause of the spreading propagation of epileptiform activity.

The relevance of hilar neurons in hippocampal physiology and pathophysiology is clear from these findings. Therefore, we felt it important to investigate further our previous findings of a difference in the kinetics of sEPSCs between AHIs and SMCs (Livsey and Vicini, 1992) by elucidating the properties of nonNMDA receptors in outside-out membrane patches excised from these neurons.

In studying these non-NMDA receptors from SMCs and AHIs, several noteworthy functional differences were observed:(1) faster desensitization rates in AHIs versus SMCs; (2) overall, faster decay in response to brief application of glutamate in patches from AHIs versus SMCs, with some noted exceptions in SMCs; (3) a greater sensitivity to cyclothiazide in SMCs versus AHIs; and (4) a larger predominant single-channel conductance in AHIs versus SMCs. In contrast, the non-NMDA receptors from the two neuronal classes shared two important features: (1) lack of significant $\mathrm{Ca}^{2+}$ permeability, and (2) linear $I-V$ relationships with a reversal potential near $0 \mathrm{mV}$.

Desensitization rates of GACs were found to be slower in SMCs versus AHIs, two neuronal subpopulations known to have strikingly different sEPSC decay rates (Livsey and Vicini, 1992), despite similar mossy fiber inputs (Amaral, 1978). This finding might suggest a functional heterogeneity of the non-NMDA receptors expressed in these two neuronal types, perhaps through differences in the expression or regulation of specific receptor subunit combinations. Specific non-NMDA receptor subunits or subunit combinations may, in fact, confer strong desensitization to the entire receptor-ionophore complex. For example, from heterogeneous combinations of GluR-A (GluR-1) and GluR-B (GluR-2) subunits of both the flip and flop versions, GluR-A-flip has been shown to permit the rapid desensitization phase in response to a glutamate step (Sommer et al., 1990). Furthermore, it has been demonstrated that homologous expression of GluR-B-flip confers a slower desensitization rate than GluR-A-flip alone, and that heterologous expression of GluR-A-flip/GluR-B-flip produces an intermediate rate (Verdoorn et al., 1991); and GluR-B similarly desensitizes slower than GluR-D alone, with the GluR-B/GluR-D combination falling in between (Burnashev et al., 1992). Overall, it has been suggested that GluR-A produces the fastest rate of desensitization, whereas GluR-B, -C, and -D produce slower rates (Jonas and Sakmann, 1992). Alternatively, mechanisms such as phosphorylation of receptor subunits (Greengard et al., 1991; Wang et al., 1991) or other second messenger-mediated processes could 
also contribute to differences in desensitization rates, similar to what has been demonstrated for many ligand-gated channels (Swope et al., 1992). These other processes might be particularly important in SMCs since it has been suggested that spines constitute a biochemically isolated compartment (Müller and Connor, 1991).

The finding of two components in the desensitization rates following prolonged glutamate steps may imply either dual populations of receptors or two desensitized conformations of the same receptor. Furthermore, the nondesensitizing plateau phase may be due to the presence of a subpopulation of receptors that do not enter into the desensitized state, to a partially open state of a single population of receptors, or to random transitions of the general population of receptors back and forth between the desensitized and open states. Given that multiple conductance states are present in the single-channel traces, it is indeed conceivable that a specific subpopulation of the receptors do not desensitize. However, the similar primary single-channel current amplitudes observed in the peak and plateau suggest that similar receptor populations are involved in both phases, although the proportion of each conductance state in peak versus plateau was not studied in detail. Furthermore, the lack of overt similarities between the channels observed in the plateau phases from the two neuronal classes prevents one from characterizing a particular nondesensitizing subtype of receptor. Finally, the larger plateau amplitude in SMCs versus AHIs does not appear to reflect differences in main single-channel conductance, since SMC channels have smaller main conductances than AHI channels. More likely, this difference reflects the rate constants between the open and desensitized states of the receptor-ionophore complex, such that the glutamate-bound receptor has a greater affinity for the desensitized state in the AHI versus the SMC. This idea fits well with the proposal that desensitization is stronger or more robust in the non-NMDA receptors of AHIs versus SMCs.

Although we do not know which subunits are expressed in the hilus, plateau amplitude has been shown to vary depending upon the expression of different splice variants of GluR-B (Sommer et al., 1990). That is, GluR-B-flip produces a larger plateau current than GluR-B-flop in response to a glutamate step. Additionally, it has been shown that CA3 pyramidal cells retain the mRNA for flip versions of the non-NMDA receptor subunits in adulthood, whereas other neurons, such as CAl cells, switch to flop variants (Monyer et al., 1991). Since SMCs are somewhat similar to CA3 pyramidal cells and showed a large plateau current in response to glutamate steps, it is interesting to speculate that GluR-B-flip is preferentially expressed in SMCs versus AHIs.

It has been suggested that non-NMDA receptor desensitization may contribute to EPSC decay rates in hippocampal (Tang et al., 1989, 1991) and chick spinal cord (Trussell and Fischbach, 1989) neurons in culture since glutamate is not rapidly degraded and will remain in the synaptic cleft until it is cleared by diffusion. However, previous theoretical work (Eccles and Jaeger, 1958) and recent whole-cell and outside-out patch studies using visual cortical slices (Hestrin, 1992) and dissociated hippocampal neurons grown in culture (Clements et al., 1992) suggest that the neurotransmitter will be cleared too rapidly from the synaptic cleft to allow desensitization to contribute significantly to the decay of synaptic currents. Clements et al. (1992) suggested that glutamate at $1 \mathrm{~mm}$ concentration will be cleared from the synaptic cleft with a time constant of about $1.2 \mathrm{msec}$. Therefore, we attempted to mimic synaptic transmission with very brief pulses of 1 mM glutamate. Our comparisons of the GACs evoked by these pulses in patches from AHIs and SMCs also demonstrated resolvable differences in the decay rates in most neurons, suggesting that properties of the non-NMDA receptor contribute to the differences in sEPSC decay rates previously described (Livsey and Vicini, 1992). Furthermore, GAC rise times were significantly slower in patches from SMCs versus AHIs, suggesting that the similar difference in sEPSC rise times probably arose from channel properties rather than from spine filtering as originally proposed. However, the finding that responses in patches from some SMCs decayed as rapidly as those in AHIs following glutamate pulses despite slow sEPSCs and slow desensitization rates demonstrates that there are still many unresolved questions. Rather, patches may vary in receptor subunit composition depending on the somatic or dendritic location, or other factors such as receptor desensitization or spine filtering may additionally slow down the synaptic decay in SMCs.

In an attempt to pinpoint further the functional differences reflecting subunit heterogeneity of non-NMDA receptors in hilar neurons, current-voltage $(I-V)$ relationships and $\mathrm{Ca}^{2+}$ permeability were investigated, since these properties are known to vary depending on the presence or absence of the edited version of the GluR-B subunit (Hume et al., 1991; Verdoorn et al., 1991; Burnashev et al., 1992) and also on that of GluR-6 (Egebjerg and Heinemann, 1993; Köhler et al., 1993). However, GACs in patches from AHIs as well as from SMCs showed linear $I-V$ relationships with no apparent inward rectification and also lacked $\mathrm{Ca}^{2+}$ permeability, suggesting the presence of GluR-B(R) or possibly another subunit conveying similar properties.

In contrast to the lack of differences in $I-V$ relationships and $\mathrm{Ca}^{2+}$ permeability, the presence of different main conductance states in the two neuronal populations strongly suggests that different non-NMDA receptor subtypes are expressed in the two neuronal classes. That is, precedents exist, with the nicotinic $A C h$ receptor and the $\mathrm{GABA}_{\mathrm{A}}$ receptor, indicating that singlechannel conductance is determined by the specific subunits constituting the receptor (Mishina et al., 1986; Verdoorn et al., 1990). Although phosphorylation (Swope et al., 1992) or other posttranslational processes may modify channel kinetics, no such processes have been shown to date to alter single-channel conductance.

Cyclothiazide is an agent that has been shown to remove nonNMDA receptor desensitization (Patneau et al., 1992; Yamada, 1992; Zorumski et al., 1993). In the hilus, this agent worked with different potencies in the two cell types. This difference is a novel finding and might also relate to the strength of desensitization conferred by the subunits expressed, to the affinity of the modulator for its binding site(s), as well as to the number and location of the binding site(s) on specific subunits or conglomerate receptors. It would be particularly interesting to determine which subunits confer sensitivity to cyclothiazide versus which contribute strongly to desensitization. The observed potency difference is of particular interest with regard to the hilus since SMCs are known to be especially vulnerable to excitotoxic damage (Sloviter, 1987; Scharfman and Schwartzkroin, 1990).

From the sum of these results, we have demonstrated functionally different non-NMDA receptors in AHIs versus SMCs. The differences observed could be due to differential expression of the molecular forms of non-NMDA subunits, or to the mod- 
ification of these subunits, perhaps due to the chemically compartmentalized microenvironment provided by the spines in SMCs, in analogy to other spiny neurons (Müller and Connor, 1991). Several important clues may already be gained and have been alluded to in the discussion of the present work in relation to the known functional properties of specific non-NMDA receptor subunits. As a challenge to future work, it will be important to determine which subunits are, in fact, expressed in the two hilar neuronal types and how they contribute to the physiology of the hippocampus and to the pathology of epilepsy.

\section{References}

Amaral DG (1978) A Golgi study of cell types in the hilar region of the hippocampus in rat. J Comp Neurol 182:851-914.

Bakst I, Avendano C, Morrison JH, Amaral DG (1986) An experimental analysis of the origins of somatostatin-like immunoreactivity in the dentate gyrus of the rat. J Neurosci 6:1452-1462.

Bettler B, Boulter J, Hermans-Borgmeyer I, O'Shea-Greenfield A, Deneris ES, Moll C, Borgmeyer U, Hollmann M, Heinemann S (1990) Cloning of a novel glutamate receptor subunit, GluR5: expression in the nervous system during development. Neuron 5:583-595.

Bettler B, Egebjerg J, Sharma G, Pecht G, Hermans-Borgmeyer I, Moll C, Stevens CF, Heinemann S (1992) Cloning of a putative glutamate receptor: a low affinity kainate-binding subunit. Neuron 8:257-265.

Blackstone CD, Moss SJ, Martin LJ, Levey AI, Price DL, Huganir RL (1992a) Biochemical characterization and localization of a non- $N$ methyl-p-aspartate glutamate receptor in rat brain. J Neurochem 58 : $1118-1126$.

Blackstone CD, Martin LJ, Price DL, Huganir RL (1992b) Structure and subunit composition of AMPA receptors in the rat brain. Soc Neurosci Abstr 18:87.

Boulter J, Hollmann M, O'Shea-Greenfield A, Hartley M, Deneris E, Maron C, Heinemann S (1990) Molecular cloning and functional expression of glutamate receptor subunit genes. Science 249:10331037.

Burnashev N, Monyer H, Seeburg PH, Sakmann B (1992) Divalent ion permeability of AMPA receptor channels is dominated by the edited form of a single subunit. Neuron 8:189-198.

Caceci MS, Cacheris WP (1984) Fitting curves to data. Byte 9:340362.

Clements JD, Lester RAJ, Tong G, Jahr CE, Westbrook GL (1992) The time course of glutamate in the synaptic cleft. Science 258:14981501.

Colquhoun D, Jonas P, Sakmann B (1992) Action of brief pulses of glutamate on AMPA/kainate receptors in patches excised from different neurones of rat hippocampal slices. J Physiol (Lond) 458:261287.

Eccles JC, Jaeger JC (1958) The relationship between the mode of operation and the dimensions of the junctional regions at synapses and motor-end organs. Proc R Soc Lond [Biol] 146:38-56.

Edwards FA, Konnerth A, Sakmann B, Takahashi T (1989) A thin slice preparation for patch clamp recordings from synaptically connected neurones of mammalian central nervous system. Pfluegers Arch 414:600-612.

Egebjerg J, Heinemann SF (1993) $\mathrm{Ca}^{2+}$ permeability of unedited and edited version of the kainate selective glutamate receptors GluR6. Proc Natl Acad Sci USA 90:755-759.

Egebjerg J, Bettler B, Hermans-Borgmeyer I, Heinemann S (1991) Cloning of a cDNA for a glutamate receptor activated by kainate but not AMPA. Nature 351:745-748.

Greengard P, Jen J, Nairn AC, Stevens CF (1991) Enhancement of the glutamate response by cAMP-dependent protein kinase in hippocampal neurons. Science 253:1135-1138.

Hamill OP, Marty A, Neher E, Sakmann B, Sigworth FJ (1981) Improved patch-clamp techniques for high-resolution current recording from cells and cell-free membrane patches. Pfluegers Arch 391:85100.

Herb A, Burnashev N, Werner P, Sakmann B, Wisden W, Seeburg PH (1992) The KA-2 subunit of excitatory amino acid receptors shows widespread expression in brain and forms ion channels with distantly related subunits. Neuron 8:775-785.

Hestrin S (1992) Activation and desensitization of glutamate-activated channels mediating fast excitatory synaptic currents in the visual cortex. Neuron 9:991-999.

Hollmann M, O'Shea-Greenfield A, Rogers SW, Heinemann S (1989) Cloning by functional expression of a member of the glutamate receptor family. Nature 342:643-648.

Hume RI, Dingledine RD, Heinemann SF (1991) Identification of a site in glutamate receptor subunits that controls calcium permeability. Science 253:1028-1031.

Isaacson JS, Nicoll RA (1991) Aniracetam reduces glutamate receptor desensitization and slows the decay of fast excitatory synaptic currents in the hippocampus. Proc Natl Acad Sci USA 88:10936-10940.

Ito I, Tanabe S, Kohda A, Sugiyama H (1990) Allosteric potentiation of quisqualate receptors by nootropic drug aniracetam. J Physiol (Lond) 424:533-543.

Jaramillo F, Schuetze SM (1988) Kinetic differences between embryonic-and adult-type acetylcholine receptors in rat myotubes. J Physiol (Lond) 396:267-296.

Jonas P, Sakmann B (1992) Glutamate receptor channels in isolated patches from $\mathrm{CA} 1$ and $\mathrm{CA} 3$ pyramidal cells of the rat hippocampal slices. J Physiol (Lond) 455:143-171.

Keinanen K, Wisden W, Sommer B, Werner P, Herb A, Verdoorn TA, Sakmann B, Seeburg PH (1990) A family of AMPA-selective glutamate receptors. Science 249:556-560.

Köhler M, Burnashev N, Sakmann B, Seeburg PH (1993) Determinants of $\mathrm{Ca}^{2+}$ permeability in both TM1 and TM2 of high affinity kainate receptor channels: diversity by RNA editing. Neuron 10:491500.

Lester RAJ, Jahr CE (1992) NMDA channel behavior depends on agonist affinity. J Neurosci 12:635-643.

Livsey CT, Vicini S (1992) Slower spontaneous excitatory synaptic currents in spiny versus aspiny hilar neurons. Neuron 8:745-755.

Lowenstein DH, Thomas MJ, Smith DH, McIntosh TK (1992) Selective vulnerability of dentate hilar neurons following traumatic brain injury: a potential mechanistic link between head trauma and disorders of the hippocampus. J Neurosci $12: 4846-4853$.

Magleby KL, Stevens CF (1972) The effect of voltage on the time course of end-plate currents. J Physiol (Lond) 223:151-171.

Mishina M, Takai T, Imoto K, Noda M, Takahashi T, Numa S, Methfessel C. Sakmann B (1986) Molecular distinction between fetal and adult forms of muscle acetylcholine receptor. Nature 321:406-411.

Monyer H, Seeburg PH, Wisden W (1991) Glutamate-operated channels: developmentally early and mature forms arise by alternative splicing. Neuron 6:799-810.

Müller W, Connor JA (1991) Dendritic spines as individual neuronal compariments for synaptic $\mathrm{Ca}^{2+}$ responses. Nature 354:73-76.

Patneau DK, Vyklicky VL, Mayer ML (1992) Cyclothiazide modulates excitatory synaptic transmission and AMPA/kainate receptor desensitization in hippocampal cultures. Soc Neurosci Abstr 18:248.

Ribak CE, Seress L (1983) Five types of basket cells in the hippocampus dentate gyrus. A combined Golgi and electron microscopic study. J Neurocytol 12:577-597.

Ribak CE, Seress L, Amaral DG (1985) The development, ultrastructure and synaptic connections of the mossy cells of the dentate gyrus. J Neurocytol 14:835-857.

Scharfman HE (1991) Dentate Hilar cells with dendrites in the molecular layer have lower threshold for synaptic activation by perforant path than granule cells. J Neurosci 11:1660-1673.

Scharfman HE, Schwartzkroin PA (1988) Electrophysiology of the morphologically identified mossy cells recorded in the dentate hilus in the guinea pig hippocampal slices. J Neurosci 8:3812-3821.

Scharfman HE, Schwartzkroin PA (1990) Consequences of prolonged afferent stimulation of the rat fascia dentata: epileptiform activity in area CA3 of hippocampus. Neuroscience 35:505-517.

Scharfman HE, Kunkel DD, Schwartzkroin PA (1990) Synaptic connections of dentate granule cells and hilar neurons: results of paired intracellular recordings and intracellular horseradish peroxidase injections. Neuroscience 37:693-707.

Sheardown MJ, Elsebet ON, Hansen AJ, Jacobsen P, Honoré T (1990) 2,3-Dihydro-6-nitro-7-sulfamoyl-benzo(F)quinoxaline: a neuroprotcctant for cerebral ischemia. Science 247:571-574.

Sloviter RS (1987) Decreased hippocampal inhibition and a selective loss of interneurons in experimental epilepsy. Science 235:73-76.

Sloviter RS (1989) Calcium-binding protein (calbindin-D28K) and parvalbumin immunocytochemistry, localization in the rat hippocampus with specific reference to the selective vulnerability of hippocampal neurons to seizure activity. J Comp Neurol 280:183-196. 
Sloviter RS, Nilaver G (1987) Immunocytochemical localization of GABA-, cholecystokinin-, vasoactive intestinal polypeptide-, and somatostatin-like immunoreactivity in the area dentata and hippocampus of the rat. J Comp Neurol 256:42-60.

Sommer B, Keinanen K, Verdoorn TA, Wisden W, Burnashev N, Herb A, Kohler M, Takagi T, Sakmann B, Seeburg PH (1990) Flip and flop: a cell specific functional switch in glutamate-operated channels of C.NS. Science 249:1580-1585.

Swope SL, Moss SJ, Blackstone CD, Huganir RL (1992) Phosphorylation of ligand-gated channels: a possible mode of synaptic plasticity. FASEB J 6:2514-2523.

Tang CM, Dichter M, Morad M (1989) Quisqualate activates a rapidly inactivating high conductance ionic channel in hippocampal neurons. Science 243:1474-1477.

Tang CM, Shi QY, Katchman A, Lynch G (1991) Modulation of the time course of fast EPSCs and glutamate channel kinetics by aniracetam. Science 254:288-290.

Trussell LO, Fischbach GD (1989) Glutamate receptor desensitization and its role in synaptic transmission. Neuron 3:209-218.

Verdoorn TA, Draghun A, Ymer S, Seeburg PH, Sakmann B (1990) Functional properties of recombinant $\mathrm{GABA}_{\mathrm{A}}$ receptors depend upon subunit composition. Neuron 4:919-928.

Verdoorn TA, Burnashev N, Monyer H, Seeburg PH, Sakmann B (1991)
Structural determinants of ion flow through recombinant glutamate receptor channels. Science 252:1715-1718.

Vyklicky L, Patneau DK, Mayer ML (1991) Modulation of excitatory synaptic transmission by drugs that reduce desensitization at AMPA/ kainate receptors. Neuron 7:971-984.

Wang LY, Salter MW, MacDonald JF (1991) Regulation of kainate receptors by cAMP-dependent protein kinase and phosphatases. Science 253:1132-1135.

Wenthold RJ, Yokotani N, Doi K, Wada K (1992) Immunochemical characterization of the non-NMDA glutamate receptor using subunitspecific antibodies. J Biol Chem 267:501-507.

Werner P, Voigt M, Keinanen K, Wisden W, Seeburg PH (1991) Cloning of a putative high-affinity kainate receptor expressed predominantly in hippocampal CA3 cells. Nature 361:742-744.

Yamada KA (1992) Thiazide diuretics reversibly block postsynaptic glutamate receptor desensitization in rat hippocampal neurons. Soc Neurosci Abstr 18:757.

Yamada KA, Rothman SM (1993) Diazoxide blocks glutamate desensitization and prolongs excitatory postsynaptic currents in rat hippocampal neurons. J Physiol (Lond) 458:409-423.

Zorumski CF, Yamada KA, Madelon TP, Olney JW (1993) A benzodiazepine recognition site associated with the non-NMDA glutamate receptor. Neuron 10:61-67. 